論交

\title{
製鉄用硫酸㳯の基礎的研究 $(\mathrm{II})^{*}$
}

\author{
秋 本 寅 一**.大 西 信三郎***” \\ FUNDAMENTAL RESEARCH OF THE CINDERS \\ AS PIG MAKING MATERIAL (II)
}

Toraichi Akimoto and Sinzaburo Onishi

\begin{abstract}
Synopsis:
There are two kinds of cinders, obtained as the residue in sulphuric açid plant. One is

(Pyrrhotite cinder $\mathrm{Pr}-\mathrm{C}$ ).

To clarify differences of the reducing behavior between these two cidners.

The cinders were investigated as follows:

(1) - Measurement of high temperature permeability at various temperature.

(2) Degree of reducibility.

The main results were as follows:

(1) Py-c was reduced easier than $\mathrm{Pr}-\mathrm{c}$ 'by $\mathrm{CO}$ and solid $\mathrm{C}$.

(2) High temperature permeability of $\mathrm{Py}-\mathrm{c}$ was better than that of $\mathrm{Pr}-\mathrm{c}$.

(To be continued)
\end{abstract} mainly composed of $\mathrm{Fe}_{2} \mathrm{O}_{3}$ (Pyrite cinder $\mathrm{Py}-\mathrm{C}$ ) and the other is mainly composed of $\mathrm{Fe}_{3} \mathrm{O}_{4}$

[眧和 30 年 11 月号 p. 1161 より続く]

\section{VII-1，高温度の通気測定装置}

Söderberg 师で“吹き上げ”現象を起して還元率を 破壊することがあるのみならず，溶融㵏お゙よび還元鉄を 飛散して電力を浪費するから危険である。

との故障を防止するために淩大層を薄くして，焙狫， 襄元を併行せしめている。

磁硫鉄鉱㵏（Pr-c）：は溶け落ちが早く，そのため瓦 斯還元が僅少で，固体還元が主体となつている故に，長 時聞を要する．一方黄鉄鉣漭 $(\mathrm{Py}-\mathrm{c})$ は前者はど溶け 落ちが早くないが耐者共に装入膡か溥いので瓦斯還元を 行うには通気をよくする必要がある。なお精錬少排気に は 70〜80\% CO を含んでいるので罟元力は相当大であ る.

通気度におよばす $\mathrm{S}$ の影偣を測定すると，

測定装置は Fig. 2 の ఏ容器に A.F.A.よる“ス タンプ"機により $6 \mathrm{~kg}$ 錘, 2in 落差, 3 回に 100〜140 mesh の試片を充填した。試料の示性分析を示すと， Table 1 の通りであるる:

試料重量：10gr, “水分 $10 \%$, 乾燥 $100^{\circ} \mathrm{C}, 24 \mathrm{hrs}$; 武片容器に磁製管（5mm
Table 1. Theoretical analysis of samples.

\begin{tabular}{|c|c|c|c|c|c|}
\hline $\begin{array}{c}\text { Sample } \\
\text { No. }\end{array}$ & $\mathrm{T} . \mathrm{Fe}$ & $\mathrm{Fe}_{3} \mathrm{O}_{4}$ & $\mathrm{Fe}_{2} \mathrm{O}_{3}$ & $\begin{array}{l}\mathrm{FeO})_{2} \\
\mathrm{SiO}_{2} \\
+\mathrm{SiO}_{2}\end{array}$ & $\begin{array}{l}\text { Re- } \\
\text { marks }\end{array}$ \\
\hline 1 & $61 \cdot 80$ & $31 \cdot 55$ & $68 \cdot 45$ & - & $\begin{array}{l}\text { Pyritie } \\
\text { cinder }\end{array}$ \\
\hline 2 & $59 \cdot 50$ & $90 \cdot 32$ & $6 \cdot 68$ & 一 & $\begin{array}{c}\text { Pyrrho- } \\
\text { tite" }\end{array}$ \\
\hline 3 & $56 \cdot 20$ & $4 \cdot 58$ & $3 \cdot 16$ & $95 \cdot 42 \%$ & $\begin{array}{c}\text { Fayal- } \\
\text { lite }\end{array}$ \\
\hline
\end{tabular}

空気漏浅防止に高温接盖剂を用いた。

測定前所要温度に $30 \mathrm{mn}$ 保持し, $500 \mathrm{cc}, 1,000 \mathrm{cc} の$

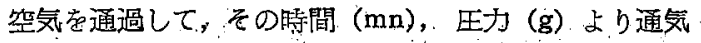
度（ $\mu$ ）部算した（A.F.A.によつた）。

VII-2 Py-c+FeS 2 測定結果 (Fig. 3)

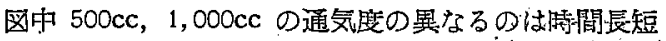
による軟化程度の相違よりきたものである：500cc は1 〜 $2 \mathrm{mn}, 1,000 \mathrm{cc}$ は 2 $5 \mathrm{mn}$ を要する.

、圧力は空気通過開始より次第に上显する傾向があるの で生力一定になつたとき測定した。

* 昭和 30 年 4 月本会菲演会にて発表

** 日本電気製鉄会社

*** 要媛大余治金教宝 


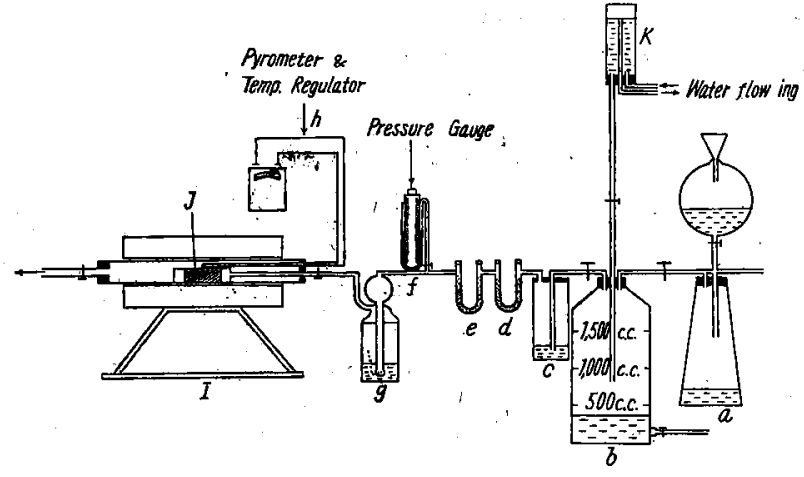

a: $\mathrm{CO}$ gas producer. b: Gas catcher. c: Conc. $\mathrm{H}_{2} \mathrm{SO}_{4}$

d: Soda-lime. e: Soda-lime. f: Pressure gauge.

g: Caustic soda sol. h: Pyrometer \& temp. regulator.

i : Eelectric furnace. $j$ : Sample container.

k: Pressure controller.

Fig. 2. Arrangement of gas reducing apparatus.
$6 \mathrm{Fe}_{2} \mathrm{O}_{3}+\frac{1}{2} \mathrm{~S}_{2}=4 \mathrm{Fe}_{3} \mathrm{O}_{4}+\mathrm{SO}_{2}$ at $600^{\circ} \mathrm{C}$ $10 \mathrm{Fe}_{2} \mathrm{O}_{3}+\mathrm{FeS}=7 \mathrm{Fe}_{3} \mathrm{O}_{4}+\mathrm{SO}_{2}$ at $550 \sim$ $850^{\circ} \mathrm{C}$

VII-3 Pr-c+FeS 測定結果 (Fig. 4)

Pr-c のみは $850^{\circ} \mathrm{C}$ まで $\mu$ は次第に減少 しているととは何等 反応せず熱膨脹による void 減少によるものと思う。

$\mathrm{FeS}_{2} ， 5 ， 10 \%$ を加えたとき $700^{\circ} \mathrm{C}$ まで 何等变化せず，それ乡上となると FeS が溶 け始め曲線傾向が变化しているのは涬粒の周 因萿層附湴して通過抵抗を減少したためと 思う.丁“应錆物砂の水分 (7\%) の適性によ る $\mu$ 最大点を表わす現象に等しい，然し $\mathrm{FeS}_{2}$ $20 \%$ ときは $\mathrm{FeS}_{2}=\mathrm{FeS}+\mathrm{S}$ の反応を容易 ならしぬ，遊離Sのため $\mu$ は急にましてい

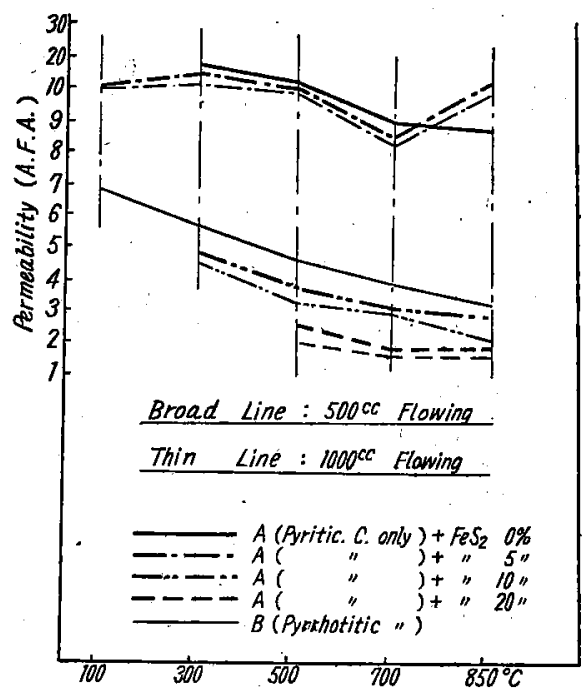

Fig. 3. Pyrite cinder $+\mathrm{FeS}_{2}$

$\mathrm{FeS}_{2}$ 即ちSが增すにつれて $\mu$ は減少し $500^{\circ} \mathrm{C}$ 以上 になると急に $\mu$ 減少は $\mathrm{FeS}_{2}=\mathrm{FeS}+\mathrm{S}$ の反応による Sの焼結によるものと考えるか然し反流温度は研究者に よつて異なる。

大体 $570 \sim 680^{\circ} \mathrm{C}$ 1であり綬漫行われるから $700^{\circ} \mathrm{C}$ まで影翼している. $700^{\circ} \mathrm{C}$ 上㣙る之 $\mathrm{FeS}+\mathrm{Fe}_{2} \mathrm{O}_{3}$ の固溶体を作るため void を生ずるので $\boldsymbol{\mu}$ はましてい る.

特に $\mathrm{FeS}_{2}$ の多い場合 $(10,20 \%)$ は次の反応により $\boldsymbol{\mu}$ 亿悪影整をおよばしている。

$3 \mathrm{Fe}_{2} \mathrm{O}_{8}+\mathrm{FeS}=7 \mathrm{FeO}+\mathrm{SO}_{2}{ }^{3)}$
るが S の溶融点以上では前二者と同様の性賀を表わ ఫ.

一般的に Py-c より Pr-c の方が $\mu$ が小である理。 由は示性分析 (Table 1) 中の $\mathrm{Fe}_{3} \mathrm{O}_{4}$ ，の影響のためで ある. 即ち $\mathrm{FeS}+\mathrm{Fe}_{3} \mathrm{O}_{4}=11 \mathrm{FeO}+\mathrm{SO}_{2}$ の文応は 1300 〜 $1350^{\circ} \mathrm{C}$ )であり, 本試験温度籍国内では起り得外.

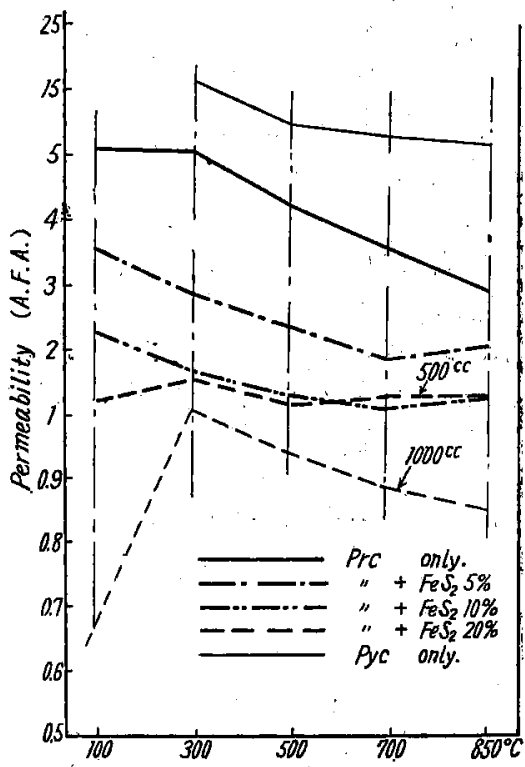

Fig. 4. Pyrrhotite cinder $+\mathrm{FeS}_{2}$

VII-4 Fayallite, $\mathrm{FeS}_{2}$ (Fig. 5)

$\mathrm{F}$ のみ場合で $700^{\circ} \mathrm{C} て ゙ \mathrm{mn} \mu$ になうているとと は説明困難であるが将来熱天科にて明らかにしたい。な お日立安来工場の結果も同様の事央方婊われている5。 


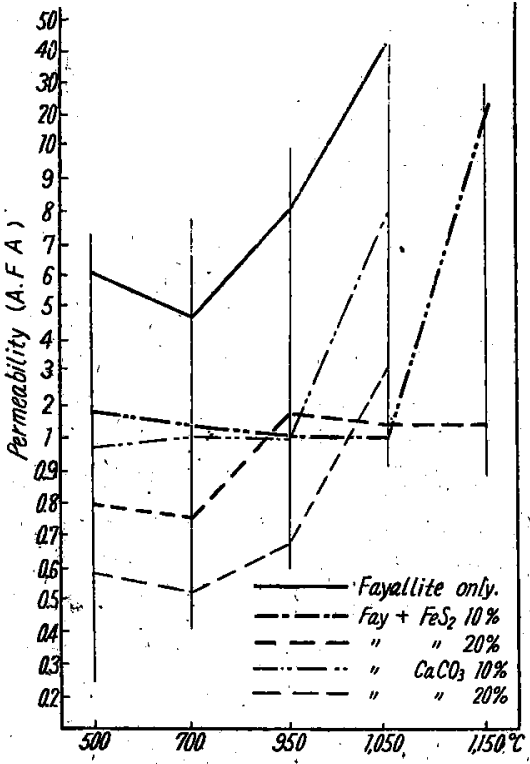

Fig. 5. Fayallite.

更に弆考のため $\mathrm{FeS}_{2}, \mathrm{CaCO}_{3}$ を混合したものの $\mu$ を示しておいた。

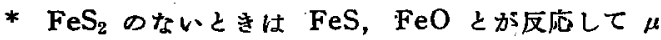
を改善するょ5に作用し， $\mathrm{FeS}_{2} 20 \%$ のときは $\mathrm{FeS}$ 多いため $1,050^{\circ} \mathrm{C}$ で粘着物を多く生じ passage を赛 いだためと思ら。

$\mathrm{FeS}+\mathrm{FeO}, \mathrm{FeS}+(\mathrm{FeO})_{2} \mathrm{SiO}_{2}$ の平衡図を示すと。 Fig. 7, 8)

** $\mathrm{CaCO}_{3} 10 \%$ 加元た場合, $950^{\circ} \mathrm{C}$ 上り $\mu$ がむし ているのは $\mathrm{CaCO}_{3}=\mathrm{CaO}+\mathrm{CO}_{2}$ のためと考える。行論 Stamping の影響のため理論分碀温度より转分ずれてい 3. $\mathrm{CaCO}_{3}$ 比重 : $2.71, \mathrm{CaO}$ 比重 $=3.2 \sim 3.40$

\section{VIII. 高温反応变化}

高温通気度測定に用いた試料の主成分は, $\mathrm{FeO} \mathrm{Fe}$ $\mathrm{FeS}_{2}, \mathrm{FeS}, \mathrm{SiO}_{2}$ であり，両㴖にはてれらの配合曼の 相違するだけである.これらの反応をあげると，

$$
\mathrm{FeS}_{2}=\mathrm{FeS}+\mathrm{S}
$$

との分解温度は $570 \sim 580^{\circ} \mathrm{C}$ group， $670 \sim 680^{\circ} \mathrm{C}$ group の研究者群に分れているが反応は紘漫反応であ 乃.

$$
\begin{aligned}
& \mathrm{FeS}+2 \mathrm{FeO}=3 \mathrm{Fe}+\mathrm{SO}_{2} \\
& \mathrm{FeS}+3 \mathrm{Fe}_{2} \mathrm{O}_{3}=7 \mathrm{FeO}+\mathrm{SO}_{2}
\end{aligned}
$$

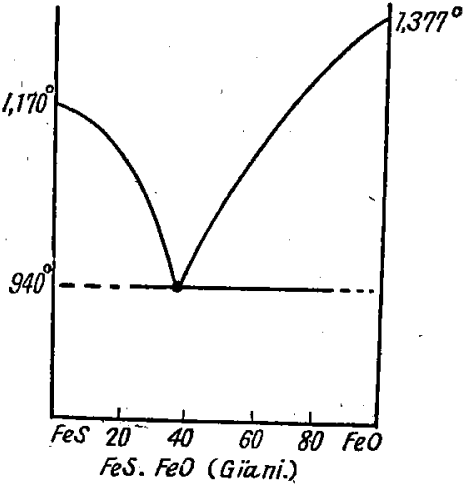

Fig. 7.

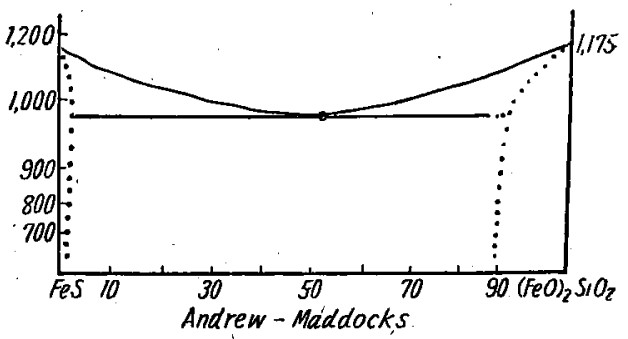

Fig. 8.

（2）は（3）に比して無視できるほよ゙僅かである。

$$
\mathrm{FeS}+11 \mathrm{Fe}_{2} \mathrm{O}_{8}=\mathrm{Fe}_{8} \mathrm{O}_{4}+\mathrm{SO}_{2}
$$

この反応は $550 \sim 850^{\circ} \mathrm{C}$ で完了するが $\mathrm{FeS}_{2}$ が多い $と^{6)}$

$$
\mathrm{FeS}+3 \mathrm{Fe}_{2} \mathrm{O}_{4}=11 \mathrm{FeO}+\mathrm{SO}_{2}
$$

これは $1100^{\circ} \mathrm{C}$ で開始し $1,300 \sim 1,350^{\circ} \mathrm{C}$ で芫了し， このとき M.Fe の一部分生成がある.

さて $\mathrm{Fe}_{2} \mathrm{O}_{3}$ の多い $\mathrm{Py}-\mathrm{c}$ は $\mu$ 方よくなつているの は（3）の反応のためである.

反対に $\mathrm{Fe}_{8} \mathrm{O}_{4}$ ，の多い $\mathrm{Pr}-\mathrm{c}$ は $\mathrm{FeS}$ との反応がより 高温である $\left(1100^{\circ} \mathrm{C}\right)$ ため, 本試験では $\mu$ に大して娈 動を表さない。

最後の fayallite の場合は Fig. 6，7 に示した如く 其晶点が案外低いために $\mu$ に大き影響を与えている。

\section{IX. 両㳯の摆元率の比較}

現在のところ cinders は眖銅法完了していないとと か灘点であるが将来 floatation によつて完全分鹤され ると思う．然し分離を完全にするには更に微細粉にする 必要があるので製鉄材料とするには低温䢱元により電気 炬投入前に高品位に㛉理する方法を考案することが肝要 である.

両反応で高酸化の $\mathrm{Fe}_{2} \mathrm{O}_{3}$ の方が解離圧力が高いから 
㴖中の殘留が多いと軟化，低溶融による面倒を生ずる ので 850 800 $\mathrm{C}$ に長く加熱して脱硫するを得策とす る.

この理由のため低温逧元調查を行つた：還元戍として はピッチコークス，CO を使用した。

\section{IX-1＼cjkstart還元装置及操作}

(a) 固体宸素還元装置 (Fig. 9)

これは低温乾燥炻 $\left(\max 200^{\circ} \mathrm{C}\right)(\mathrm{C})$ の中へ,ニクロ ムの高温炉 (D) を入れて，C 炉中へ producer gas をH のパイプに上つて送り込み，压力計 (E)，水分 吸収器 (F) によつで一定量の酸化防止ガスを送り込ん

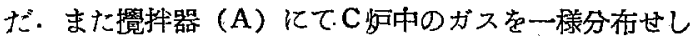
引排気管（G）より使用济みの排気を放出した。

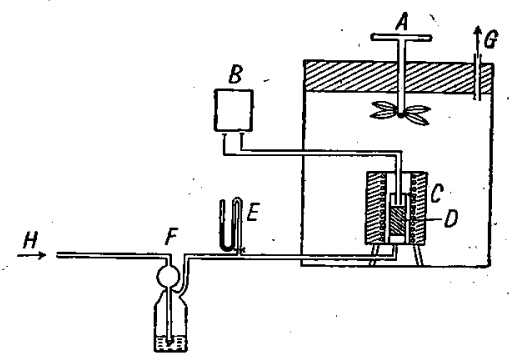
A: Fan agitator
B: Pyrometer \& temp. regulator
$\mathrm{C}:$ Inner furnace $\left(850^{\circ} \mathrm{C}\right.$ and under)
D: Sample container
$E$ : Pressure gauge
F : Soda solution
G: Gas exhauster
$\mathrm{H}$ : Gas inlet for use of atm. controlling

Fig. 9. Arrangement of solid carbon reducing apparatus.

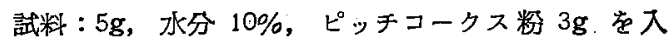
念温合して試片容器に stamping (A.F.A) し, 100 ${ }^{\circ} \mathrm{C}$ で $12 \mathrm{hrs}$ 乾燥した。 まずC炉を密閉して producer gas を送り込み $\left(100^{\circ} \mathrm{C} / \mathrm{mn}\right)$ 所要温度に $\mathrm{D}$ 灯がなると

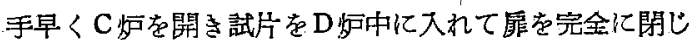
る.

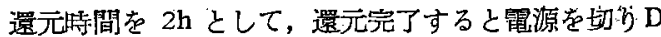

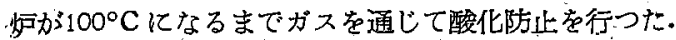
常温になると武料を取仙して分析材料とした。

(b) 瓦斯䢬元装置 (Fig. 2)

$\mathrm{CO}$ は蜮酸と濃 $\mathrm{H}_{2} \mathrm{SO}_{4}$ 亿発生せしめ, 苛性ソーダ, $\mathrm{CaCl}_{2}$ Conc $\mathrm{H}_{2} \mathrm{SO}_{4}$ 亿 $\mathrm{CO}_{2}$, 水分除去した。

CO を一定压力にするためにレペラー（n）虹用いた $\left(10 \mathrm{~mm} \mathrm{H} \mathrm{H}_{2} \mathrm{O}\right)$ 武片容器纪磁製パタブ $(5 \mathrm{~mm} \phi)$ をフ ラックにさし込み，高温按着剤で漏㾝防止した。
CO 通過量 $\cdot 3,000 \mathrm{cc}$
温度調節 スライダッタ
ガス送入速度 $100 \mathrm{cc} / \mathrm{mn}$

IX-2 還元結果

(a) 分析方法は JES によつた。

(b) 分析結果 (Table 2,3)

\section{X. 還元率の計算 (Fig. 10)}

還元生成物の分析結果は Table 2，3 亿示す。 勿論固体崖素還元では還元㧩のピッチコークスが残留 しているので原㴖中の全鉄より著しい低い全鉄を示して いる. また $\mathrm{CO}$ 還元の場合も還元操作するとき deposit carbon を生じているので前者はど全鉄には相違はない が幾分還元生成物の方が低い值を示している.との deposit carbon $\Phi$ 発生量到 $500 \sim 600^{\circ} \mathrm{C}$ の主案外多 量である（炭素を差引いた）

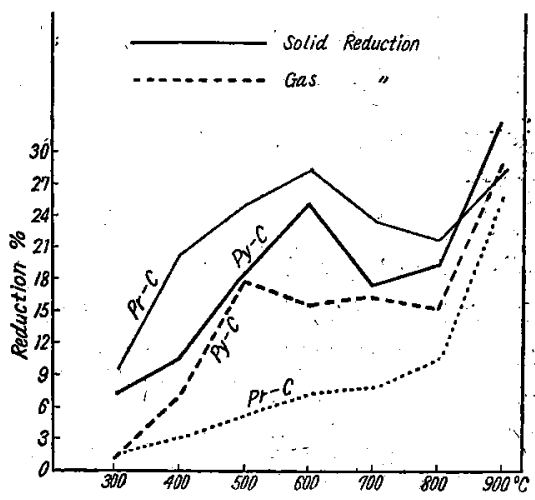

Fig. 10. Relationship between degree of reduction and temperature.

還元事の計算式は次のものにようた7?.

$$
\begin{aligned}
& \mathbf{R}_{\mathbf{1}}=\frac{\mathrm{e}^{\prime} \mathbf{c}^{\prime} \cdot 0 \cdot 259}{\mathbf{d}^{\prime}} \times 100-\frac{\mathrm{e}_{\mathbf{1}}+\mathrm{c} \cdot 0: 259}{\mathrm{~d}} \times 100 \cdots(6) \\
& \mathrm{e}^{\prime} \text { ………還元䓈の金属鉄\% } \\
& \text { c'.......... " FeO \% } \\
& \text { d' } \mathrm{d}^{\prime} \ldots \ldots . . . . . \text { " Total Fé } \% \\
& \text { e …………還元前の金属鉄 } \% \text { \% } \\
& \text { c................. } \mathrm{FeO} \% \\
& \text { d.........." : } \text { 'Totàl Fe \% } \\
& 0 \cdot 259=\frac{\mathrm{Fe}}{\mathrm{FeO}} \times \frac{1}{2} \text { (分子量比口 }
\end{aligned}
$$

\section{XI. 両漳に対する考察}

との項で㟫元結果仪対して考察すると， 
Table 5

\begin{tabular}{|c|c|c|c|c|c|}
\hline \multirow{2}{*}{ Mines } & \multirow{2}{*}{$\begin{array}{l}\text { Reducing } \\
\text { temp. }\end{array}$} & \multicolumn{2}{|c|}{$\mathrm{CO}$ gas } & \multirow{2}{*}{ Deposit C. } & \multirow{2}{*}{ Reduction \% } \\
\hline & & Vol. & Flow speed & & \\
\hline $\begin{array}{c}\text { Kamaishi }(10 \mathrm{~g}) \\
\text { " } \\
\text { Kainanto } \\
\left(\mathrm{Fe}_{2} \mathrm{O}_{3}\right) \\
" \text { " } \\
\text { " } \\
\text { " }\end{array}$ & $\begin{array}{l}500^{\circ} \mathrm{C} \\
700 \\
500 \\
500 \\
700 \\
750 \\
1,000\end{array}$ & $\begin{array}{l}9 \\
9 \\
18 \\
21 \\
25 \cdot 2 \\
27 \\
36 \cdot 6\end{array}$ & $\begin{array}{c}100 \mathrm{cc} / \mathrm{mn} \\
" 1 \\
" \\
" \\
" \\
" \\
"\end{array}$ & $\begin{array}{c}0 \cdot 20 \% \\
0 \cdot 17 \\
18 \cdot 20 \\
19 \cdot 14 \\
7 \cdot 98 \\
11 \cdot 40 \\
9 \cdot 00\end{array}$ & $\begin{array}{l}2 \cdot 12 \% \\
16 \cdot 48 \\
45 \cdot 04 \\
53 \cdot 74 \\
53 \cdot 42 \\
72 \cdot 75 \\
89 \cdot 56\end{array}$ \\
\hline
\end{tabular}

（A） 固体崖素の還元の場合

ヘマタイトはマグネタイトより還元しやすい,また揮 発分の多いものは少ないものより還元力が大きい，例え ば褐孷，木宸，半成コークス，樹脂炭，コークスの順序 に還元力は減少してくる
Pyrite cinder. pitch coke (2hrs) $900^{\circ} \mathrm{C}$

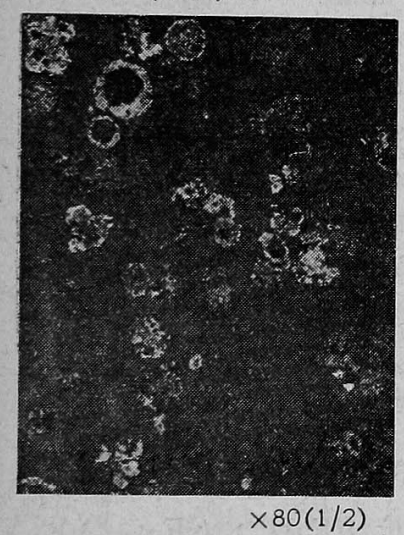
pitch coke (2hrs) $900^{\circ} \mathrm{C}$

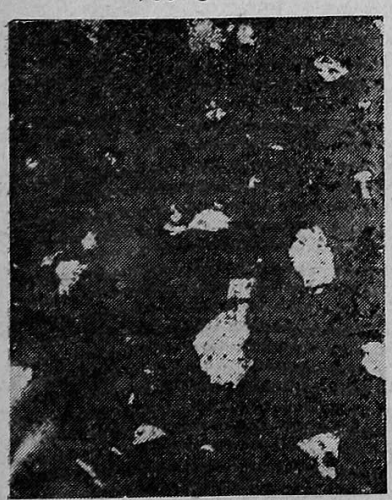

$\times 80(1 / 2)$
Pyrrhotite cinder.
Pyrite cinder. $\mathrm{CO}$ gas $(3,000 \mathrm{cC}) 900^{\circ} \mathrm{C}$

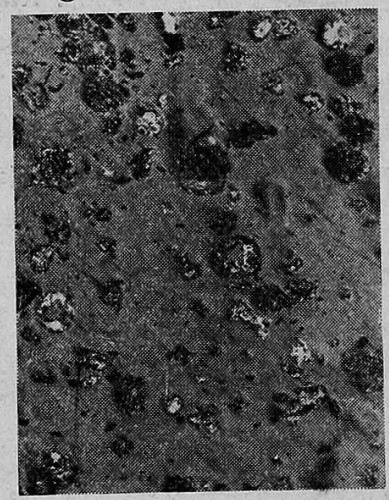

$\times 80(1 / 2)$

Pyrrhotite cinder. CO gas $(3,000 \mathrm{cc})$ $900^{\circ} \mathrm{C}$

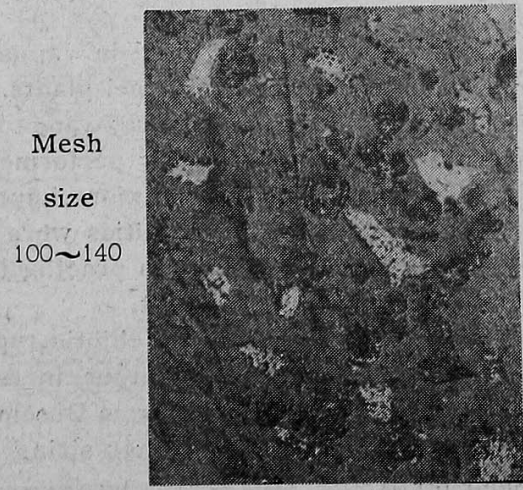

$\times 80(1 / 2)$
Photo. 1. Microstructure of reduced products.
コークスによる還元を述べると ${ }^{10)}$

ヘマタイトは約 $400 〜 500^{\circ} \mathrm{C} て ゙$ 還元能力を有している $\left(\mathrm{Fe}_{2} \mathrm{O}_{3} \rightarrow \mathrm{FeO}\right),(\mathrm{FeO}-\mathrm{Fe})$ が $800^{\circ} \sim 900^{\circ} \mathrm{C}$ になら ないと $\mathrm{FeO}$ - $\mathrm{Fe}$ の還元は著しくない，そうして800〜 マグネタイトはコークス中の四掂“ガ ス”で却つて酸化され $800 \sim 900^{\circ} \mathrm{C}$ で $\mathrm{Fe}_{3} \mathrm{O}_{4}-\mathrm{FeO}$ が多く表われ $900 \sim 1,000$ ${ }^{\circ} \mathrm{C}$ で最高となる.

然し硫酸滓は還元武験前に0・3〜0・5 \% Fe を含んでいる.とれが試駼中 そ表われ恰を金属還元鉄が発生したか の㛎き有様を示す。

(B) 瓦斯の還元

瓦斯流の容積大小，鉱質，酸化度に より著しく還元率は相違する。

酸化度の大さい $\mathrm{Fe}_{2} \mathrm{O}_{3}$, limoniteは $300 \sim 600^{\circ} \mathrm{C}$ の低還元温度で $\mathrm{Fe}_{2} \mathrm{O}_{3}$ $\mathrm{FeO}$ の反応がすすみかつ金属還元鉄 生成の傾向を示す（千分の 1 単位）

$\mathrm{Fe}_{3} \mathrm{O}_{4}$ は $400 \sim 500^{\circ} \mathrm{C}$ で還元を開 炲する.

結局低温還元で $700^{\circ} \mathrm{C} \sim 1,100^{\circ} \mathrm{C}$ 間では $\mathrm{Ee}_{2} \mathrm{O}_{3}$ は $\mathrm{Fe}_{3} \mathrm{O}_{4}$ に比して還元 が容易である.

田独の $\mathrm{Fe}_{2} \mathrm{O}_{3}$ は $500^{\circ} \mathrm{C}$ で $\mathrm{Fe}_{2} \mathrm{O}_{4}$ に完全变化している.（II報にて porosity，表面積などより論不する)

deposit carbon の発生 ${ }^{11}$ は同一条 件にて CO gas flowing すると

$\mathrm{Fe}_{2} \mathrm{O}_{3} \cdots$ deposit carbon $=18 \sim 10 \%$ $\mathrm{Fe}_{3} \mathrm{O}_{4} \ldots$ " " " $=0 \sim 2 \%$

実際鉣石による deposit carbonの 発生を示すと ${ }^{21)} \mathrm{CO}$. ガス還元はある 
限度まで速やかに還元するがそれ以上になると，Reduction を行わず $2 \mathrm{CO} \rightarrow \mathrm{CO}_{2}+\mathrm{C}$ の解離反応のみを進行 するものである.

さて CO gas の Flowing speed が大いに関係する が本研㚾では， $100 \mathrm{cc} / \mathrm{mn}$ の速度で $30 \mathrm{mn}$ 行つた結果 を analysisして還元器を計算したものである.

還元結果：Initial metallic Fe は Pr-C 中に多くあ り $0.5 \% \mathrm{Fe}$ 内外であり $\mathrm{Py}-\mathrm{C}$ では $0.2 \sim 0.3 \% \mathrm{Fe}$ の程度である。

両涪の Reduction において Solid carbon reduction では Fig. 8 に示す如く $\mathrm{Fe}_{8} \mathrm{O}$ 、の多い Pyrrhotitie cinder の方峸續よく，低級酸化物 $\left(\mathrm{Fe}_{3} \mathrm{O}_{4}\right)$ を より多く含有しているために酸素除去量が少くてすむか らである.

CO gas reduction では酸化度の高い Py-C は酸 化度の低いPr-Cより還元効果が大である.（政報にて 論文する）てれは内筫の状態によるもので表面積および 織維状 Hematite その他が重大なる項目となるが Deposit carbon の㲜生が還元進行を左右することは論 を俟たないから将来表面積の大小，Flowing speed の 速遅などによる Deposit carbon の発生量と併せ研究 しこの疑問点を明確に論及したい.
参考のだめ還元生成物の顕数鑜写真を添入しておく. なお写筫は住友金属鉱山選鉱場の津乗技師の協力による ものであるから紙面を借りて感詓の意を表します（つ づく）(昭和 30 年 5 月答稿)

\section{交 献}

1) $\left\{\begin{array}{l}\text { Reuleaux: Met Erz } 24 \text { (1927) 102 } \\ \text { 茄村平八: Chem. Met. Eng. } 24 \text { (1921) } 437\end{array}\right.$

2) Hŭtting. $u_{i}$ Luremann: Z. Angew chem. 39 (1926) 759

3) I. Heike: St u. Ei. 33 (1913) 813

4) 水㬏会誌：11（昭 17-年） 229

5) 鉄已鈰: 39 (昭 28 年) 299

6) Diepschlog \& Horn: Arch. Eisenhuttenwes $4(1930 / 31375)$

7）佐々木茂式：鉄と銧，10（明27）83

8) Mellor: 14 (Fe part) 775

9) J. Klarding: St u. Ei. 58 (1938) 1,143

10）俈々末茂二：銧と銀，11（昭28） 1,221

11) Bone Reeve \& Saunder: J. Inst, iron and steel advance copy No. IN (1930) 1 48.

12）位々本茂二：鉄と鎘，11（昭28）1221

\section{高炉作業の改善に就いで \\ 堺 千 代次 ${ }^{* * *}$}

\section{ON IMPROVEMENTS OF THE BLAST FURNACE PRACTICE}

\section{Chiyoji Sakai}

Synopsis:

No. 2 blast furnace in Kokura Steel Works which started in January 1951, is now producing the low copper, low sulphur pig iron to be used for steel plants.

Recently, in order to increase the output, to decrease coke ratio and to improve the pig quality, improvements in the blast furnace practice was thoroughly performed as follows:

1) Preparation and controlled use of raw materials was more improved.

2) Sinter production was increased more and sinter qualities were more improved.

3) In the furnace operation, the slack-wind-blowing was practiced and the blast pressure was controlled and charging method was found out the best.

4) Tuyeres were changed from the circular type to the elliptic type.

As results of this improved operation, espeçially the autput increased to over $400 \mathrm{t} / \mathrm{day}$, and the coke ratio decreased below 0.700, during the period from December 1953 to April 1954.

This improvement presumably depends mainly on the better sizing of raw materials as well as on the furnace operation matched for it:

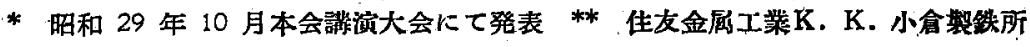

